\title{
Os espaços do brincar em uma escola sem brinquedos: o que nos falam as crianças?
}

\author{
The spaces of playing in a school without toys: \\ what do children tell us?
}

\author{
Jader Janer Moreira LOPES ${ }^{1}$ \\ Maria Renata Prado MARTIN²
}

\begin{abstract}
Resumo
Este artigo parte de uma pesquisa de pós-doutorado que pretende analisar o ponto de vista de crianças de 6 anos sobre os espaços do brincar dentro de uma escola sem brinquedos. Para isso, utiliza-se do aporte teórico do campo de estudos da Sociologia da Infância e da Geografia da Infância, além de referências da Teoria Histórico Cultural e dos teóricos que tratam do brincar. Foram realizadas observações, registro de entrevistas e desenhos produzidos pelas crianças de uma escola da cidade de Vitória-ES. Para a compreensão das vivências das crianças a metodologia adotada foi a elaboração de mapas vivenciais.
\end{abstract}

Palavras-chave: Geografia da Infância. Mapas vivenciais. Espaços Educacionais.
Abstract

This article is part of a postdoctoral research that intends to analyze the point of view of children of 6 years on the spaces of playing inside a school without toys. For this, we use the theoretical contribution of the field of studies of the Sociology of Childhood and the Geography of Childhood, as well as references of Cultural Historical Theory and theorists who deal with play. The children of a school in the city of Vitória-ES produced observations, interviews and drawings. In order to understand the children's experiences, the methodology adopted was the elaboration of experiential maps.

Keywords: Geography of Childhood. Experiential maps. Educational Spaces.

1 Possui graduação em Geografia pela Universidade Federal de Juiz de Fora (1989), mestrado em Educação pela Universidade Federal de Juiz de Fora (1998), doutorado em Educação pela Universidade Federal Fluminense (2003) e pós-doutorado pelo Internationaler Promotionsstudiengang Erziehungswissenchaft/PsychologieINEDD, da Universität Siegen, Alemanha. Atualmente é professor do programa de pós Graduação em Educação da Universidade Federal Fluminense e da Universidade Federal de Juiz de Fora, onde orienta mestrado e doutorado. Pesquisador da FAPERJ, do CNPq e CAPES. E-mail: jjanergeo@gmail.com.

2 Psicóloga formada pela Universidade Federal do Espírito Santo (2002), com mestrado (2003) e doutorado (2008) pela Universidade de Paris 8. Pós doutorados pela Universidade Federal de Juiz de Fora (2014) e pela Universidade de Paris Descartes (2019). Hoje é coordenadora de curso do Centro de Formaçáo da Essonne e professora contratada da Universidade de Cergy Pontoise. E-mail: mariarenataprado@gmail.com.

\begin{tabular}{|l|l|l|l|l|l|}
\hline R. Educ. Públ. & Cuiabá & v. 28 & n. 69 & p. 625-649 & set./dez. 2019 \\
\hline
\end{tabular}




\section{Introdução}

$\mathrm{O}$ rio que fazia uma volta atrás de nossa casa era a imagem de um vidro mole que fazia uma volta atrás de casa./Passou um homem depois e disse: Essa volta que o rio faz por trás de sua casa se chama enseada./Náo era mais a imagem de uma cobra de vidro que fazia uma volta atrás da casa./Era uma enseada/Acho que o nome empobreceu a imagem. Manuel de Barros (2001, p. 25).

Manuel de Barros, poeta brasileiro, autor da epígrafe que abre este texto, nascido no estado do Mato Grosso, falecido no ano de 2014, tem sido constantemente evocado quando se fala de crianças e infâncias. Suas palavras, que valorizam a condição brincante e inventiva do ser humano, aportam nos fragmentos constantemente ignorados do meio para compor suas narrativas de mundo. Os desperdícios são seus vícios linguageiros e as crianças, as infâncias, suas próprias memórias de pequeno, são convidadas em suas constâncias! Emergem em suas palavras! Criadoras de novos lugares e (con)textos, nelas se encontram as cobras de vidros enquanto as enseadas não existem. As voltas atrás da casa convidam para travessias histórico-geográficas plenas de achados. $\mathrm{O}$ poeta é um caçador de achadouros da infância, assumido! Em suas palavras:

Acho que o quintal onde a gente brincou é maior do que a cidade. A gente só descobre isso depois de grande. A gente descobre que o tamanho das coisas há de ser medido pela intimidade que temos com as coisas. Há de ser como acontece com o amor. Assim, as pedrinhas do nosso quintal são sempre maiores do que as outras pedras do mundo. Justo pelo motivo da intimidade. Mas o que eu queria dizer sobre o nosso quintal é outra coisa. [...] Mas eu estava a pensar em achadouros de infâncias. Se a gente cavar um buraco ao pé da goiabeira do quintal, lá estará um guri ensaiando subir na goiabeira. Se a gente cavar um buraco ao pé do galinheiro, lá estará um guri tentando agarrar no rabo de uma lagartixa. Sou hoje um caçador de achadouros de infância. Vou meio dementado e enxada às costas a cavar no meu quintal vestígios dos meninos que fomos. (BARROS, 2010, p. 67).

Os vocábulos do autor inspiram nossos achadouros nos liames que as crianças estabelecem com seus espaços geográficos, com seus meios vividos. Olhar as cobras de vidro ante a iminência de se transformarem em enseadas e, com isso, 
reconhecer a infância e a constante atividade criadora que a forma. Estar com as crianças atracadas em suas escalas cotidianas, mas indo sempre além delas, ter no entorno e na corporeidade a unidade sem limites explícitos do eu-mundo, fronteiras onde se situam nossas investigações.

Este artigo busca compreender o ponto de vista de crianças de 6 anos sobre os espaços do brincar dentro de uma escola considerada por elas sem brinquedo. Para compreender a questáo que nos inquieta, dialogamos com o aporte teórico do campo de estudos da infância, a Sociologia da Infância, a Geografia da Infância, além de referências da Teoria Histórico-cultural de Lev S. Vygotsky, palavras em torno das quais construiremos nossos argumentos.

\section{Como as crianças experenciam o espaço urbano? Ou alguns postulados teóricos}

Até agora, não houve nenhuma tentativa de questionar "o espaço de vida urbana” ou respondê-la cientificamente. Em ambas literaturas, psicológica e pedagógica, "a criança" tem sido simplesmente um objeto de pesquisa. Os poucos e recentes estudos que contrastam a criança da cidade e a criança rural não oferecem uma análise detalhada, nem descrição da realidade da vida na cidade, nem tentam capturar o "espaço de vida" da criança urbana. (MUCHOW E MUCHOW, tradução livre, 2012, p. 78).

A pergunta e a epígrafe presentes são de Marta Muchow, autora alemã que viveu no início do século XX e morreu tragicamente, diante da expansão nazista naquele país. Seus trabalhos, desenvolvidos nos anos 1930, já traziam um conjunto de questionamentos e inquietaçóes que fazem parte dos contemporâneos estudos da infância. Temas como protagonismo das crianças, ponto de vista infantil, vivências e experiências no espaço, críticas aos modelos positivistas, tensóes metodológicas de investigação são alguns princípios presentes em seu trabalho, ainda bem desconhecido em território brasileiro.

Se, hoje, a Sociologia da Infância considera a infância como categoria social, com características e uma cultura próprias, e os estudos sociológicos têm sustentado a autonomia das formas culturais da infância (DENZIN, 1977; CORSARO, 1997; JAMES; JENKS; PROUT, 1998; PROUT, 2000), Muchow (2012), sem dúvida, já debatia tais premissas com relativo pioneirismo.

Apoiando-se em tais premissas e assumindo, como Sarmento (2004, p. 21), a legitimidade das culturas infantis, nas palavras do autor: 
[...] sem prejuízo de análise dos factores psicológicos e das dimensóes cognitivas e desenvolvimentais que presidem à formação do pensamento das crianças, as culturas da infância possuem, antes de mais, dimensóes relacionais, constituem-se nas interacçóes de pares entre crianças e adultos, estruturando-se nessas relaçôes formas e conteúdos representacionais distintos.

Buscamos reconhecer a atividade criadora das crianças e suas potências na gênese do novo, no princípio do inexistente, na origem de uma história outra que se configura nas paisagens geográficas herdadas em cada geração. A Sociologia da Infância vai, ao contrário da concepção clássica durkheimiana, considerar a criança como parceira do seu processo de socialização, sendo não somente produzida, mas se produzindo, participando das trocas, construindo-se resistindo, adaptandose, submetendo-se ao projeto educativo e social que é elaborado para elas. As crianças não são integralmente submissas às lógicas sociais e tampouco às lógicas deterministas da reprodução como vítimas passivas de traumatismos ocorridos em sua infância.

As culturas da infância exprimem a cultura societal em que se inserem, mas o fazem de modo diferente da cultura adulta. Torna-se, então, necessário reconhecer os traços distintivos das culturas da infância, dos quais o brincar é um deles. Por meio de pesquisas realizadas no campo da Sociologia da Infância (SARMENTO, 2007; SIROTA, 1998), podemos compreender como a criança reelabora, interpreta e transforma os projetos educativos e sociais elaborados pelos adultos. Segundo Julie Delalande (2004), uma das questôes fundamentais é saber como funciona esta cozinha que faz com que a criança se torne um indivíduo social. Pensar nessa questão quer dizer tentar compreender como o indivíduo entra na sociedade, descobre suas normas, internaliza-as e transforma-as. Estamos, assim, longe de considerar a criança como um sujeito submisso aos estágios de desenvolvimento social, moral e de linguagem. Segundo Danic, Delalande e Rayou (2006, p. 28), "a ideia de uma transmissão de saberes, de competências de um adulto a uma criança passiva é suplantada pela concepção de um processo em parte consciente e em grande parte inconsciente, pelo qual os protagonistas constroem disposiçóes, adquirem conhecimentos e gestos."

Outro campo de estudos que nos ajuda a entender as relaçóes das crianças com seus espaços é a Geografia da Infância. Esse domínio teórico tem como questão principal a compreensão da infância em seus diferentes contextos geográficos, permeados pelas escalas em suas inserçóes diversas (quer em fronteiras oficiais ou simbolicamente construídas). Compreender como as infâncias são constituídas pelos variados arranjos culturais e sociais, pela 
diversidade geográfica e, também, como as crianças se apropriam e configuram suas diferentes geografias, são alguns dos propósitos dessa área de estudo. Assim como na Sociologia da Infância, a criança é considerada como ser social que participa ativamente da sociedade e do meio em que vive, assumindo sua condição histórica, cultural e geográfica.

Nesse debate, um conceito torna-se fundamental, o de vivência, o que nos remete, obrigatoriamente, aos trabalhos sistematizados por Lev S. Vygotsky, conhecido autor da Bielo-Rússia, cuja vida foi passada na antiga Uniáo Soviética. Esse vocábulo tem sido fundamental, não apenas na reflexão da interface das crianças com seus espaços, inclusive os do brincar, como é o foco desta pesquisa, mas também em sua dimensão metodológica. Se perguntas como de que forma as crianças tomam consciência e concebem esses espaços? como elas se relacionam com eles e com as outras crianças? fazem parte de nossas investigações, elas são sempre seguidas de outras: como elas os desenham? como os registram? (Prado, 2018), além de muitas outras.

Vygotsky (2010, p. 691) aponta que, na vivência, são levadas em conta todas as particularidades que participam da determinação de sua atitude diante de uma dada situação. Assim,

[...] o meio não pode ser analisado (...) como uma condição estática e exterior com relação ao desenvolvimento, mas deve ser compreendido como variável e dinâmico. Então o meio, a situação de alguma forma influencia a criança, norteia o seu desenvolvimento. Mas a criança e seu desenvolvimento se modificam, tornam-se outros. E não apenas a criança se modifica, modifica-se também a atitude do meio para com ela, e esse mesmo meio começa a influenciar a mesma criança de uma nova maneira.

Vemos aí a condição dinâmica da vivência. Criança e meio estão em constante troca, em constante modificação a partir da ação de ambos. A ação da criança sobre o meio modifica-o, mas também o meio modifica a própria criança, ou seja, "as vivências espaciais são unidades formadoras de nossas subjetividades, de nosso ser e estar no mundo." (Lima, 2019, p.04). Nesse processo, o brincar torna-se uma atividade fundamental.

Brincar, então, significa vivenciar de determinada forma um espaço geográfico e um tempo histórico, sendo que as vivências dessas duas dimensóes vão modificando a forma como a criança se desenvolve e aprende. Esse entre lugaré onde se encontra o que Vygotsky (obras diversas) denominou Obutchenie (PRESTES, 2012), considerado aqui como uma atividade que gera desenvolvimento. 
Tendo as crianças como protagonistas da pesquisa, buscaremos entender a forma como vivenciam o brincar no contexto onde se encontram inseridas e como esse se presentifica nas relaçóes espaciais que fazem parte do seu cotidiano.

\section{Mapas vivenciais: considerações metodológicas para entender as lógicas infantis e suas espacialidades}

[...] mapas são profundos, voraginosos, indomesticáveis.

Como pode o homem conceber o mapa?

Aqui rios, aqui montanhas, cordilheiras, golfos, aqui florestas, tão assustadoras quanto os mares.

As legendas dos mapas são tão belas que dispensam as viagens. Você está louca, dizem-me, um mapa é um mapa. Não estou, respondo.

O mapa é a certeza de que existe O LUGAR [...]

(ADÉLIA PRADO, 1981, p. 51)

"O mapa é a certeza que existe o lugar." (PRADO, 1981, p.51). Com essas palavras, a poetisa mineira Adélia Prado nos conclama a assumir o mapa como algo que não apenas registra, carrega o lugar, mas como também o cria, narra e materializa sua existência para o outro. E é com os mapas que chegamos até as crianças de uma determinada escola, situada no estado do Espírito Santo, Brasil. Nossa chegada se dá a partir do conceito de vivência, que, como expresso, reconhece a unidade entre a criança e o meio, onde se inaugura o novo, o inexistente.

É na fusão entre os mapas e o conceito de vivência que Lopes (2015, no prelo) traça uma metodologia de investigação que vem sendo chamada de mapas vivenciais, que se caracterizariam por ser

[...] movimentos de representaçóes cartográficas que tragam não só elementos do mundo adulto (Cartografia para Crianças), mas também as referências das próprias crianças, as suas lógicas próprias presentes nos diferentes momentos do seu desenvolvimento, constitui-se em promover ofertas geo-cartográficas que possam se encontrar, daí uma cartografia com crianças, reafirmando as singularidades constitutivas do ser humano. 
Ainda, segundo o autor:

Nos mapas vivências partimos desses espaços ofertados e a partir da pergunta que orienta a pesquisa, traçamos com as crianças a produção do material de pesquisa. Para isso, assumimos também as múltiplas linguagens infantis (do desenho, da narrativa oral, das expressôes corporais, das relaçóes intermodais e outras) na produção do novo, do inexistente, ou seja, nosso desejo é resgatar os indícios do espaço desacostumado como uma das principais particularidades da discursividade e do linguageiro infantil. (LOPES, 2015, no prelo)

Para a realização dos mapas vivenciais e para a compreensão das vivências das crianças, foram realizadas observaçóes participantes, registro de entrevistas e desenhos realizados pelas crianças de 6 anos que cursam o $1^{\circ}$ ano do Ensino Fundamental em uma escola em Vitória (cidade da regiáo sudeste do Brasil).

Apesar de mudanças recentes em sua direção e origem (a instituição pertencia a uma rede confessional), a escola apresenta alguns problemas relacionados em seu arranjo espacial. Segundo a diretora, "faltam espaços para o recreio das crianças." (Nota de campo, 2014). As professoras também ressaltam essa posição. De acordo com uma delas, "as crianças só correm no pátio, por falta de estrutura... bom seria se tivesse um parquinho." ${ }^{3}$ (Nota de campo, 2014). Para paliar a falta de brinquedos, essa professora instaurou o dia do brinquedo na sexta-feira, quando, segundo ela, "eles trazem os brinquedos e brincam juntos, coletivamente."

Eu faço isso toda sexta-feira. A Paula já chegou com um brinquedinho dentro da bolsa. Eu falei assim: Hoje é dia do brinquedo? Aí ela: Não, tia, só trouxe pra você poder ver. Eu: Aham, a tia já viu, agora guarda! Mas no final, se der um tempinho eu deixo, não tem problema não, relata a professora. (Nota de campo, 2014)

Ver Croqui 1. 


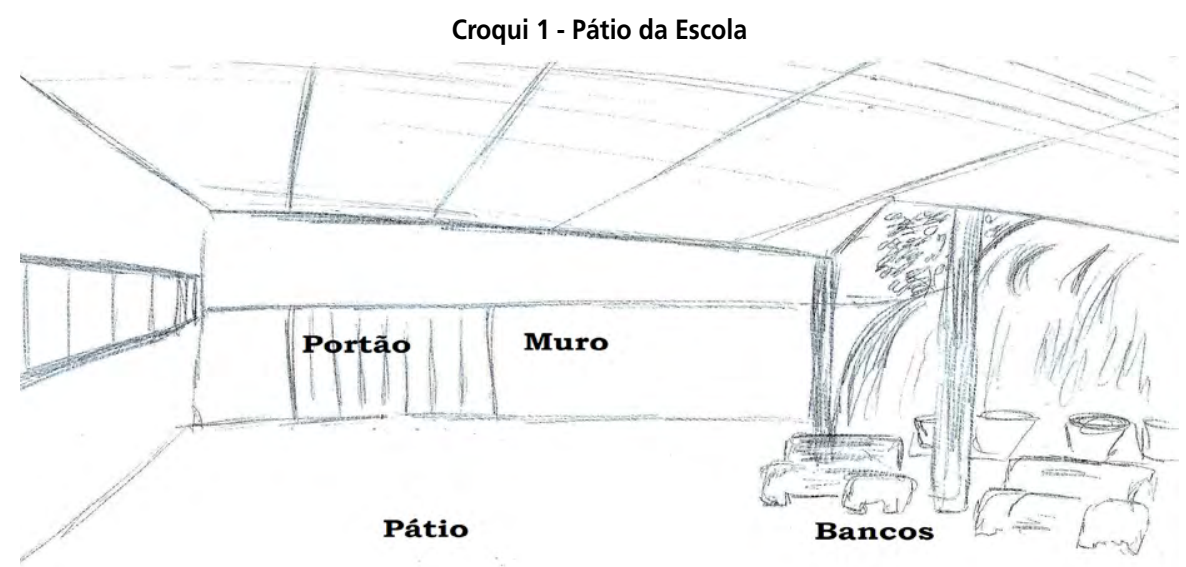

Fonte: Trabalho de Campo - 2014

Nesse local, com os princípios dos mapas vivenciais, iniciamos nossas conversas com as crianças. Duas conjunturas estavam conosco: Qual o significado de brincar para elas? - e, para isso, solicitamos que desenhassem e nos falassem sobre seus espaços de brincar. A escolha das crianças, em torno de 10, foi feita pela professora. As conversas e a produção do mapa ocorreram em uma sala separada em grupo de dois. O quadro a seguir traça a metodologia:

\section{Quadro 1: Mapas vivenciais}

Momento 01

Momento 02

Momento 03

Desenhando e conversando
Solicitou-se que cada criança desenhasse em uma primeira folha A3 a escola onde estudavam

Em uma segunda folha A3 transparente, colocada em cima da primeira folha, onde estava representada a escola, pedimos que desenhassem seus espaços de brincar

Em uma terceira folha $A 3$, pedimos que desenhassem a escola que desejariam, a escola ideal na qual gostariam de estudar.

À medida que os desenhos foram produzidos, ocorreu a conversa articulada com eles. Assim, o que foi dito tem uma relação íntima com o que foi desenhado pelas crianças. 
Foram realizados 30 desenhos. A professora também realizou três desenhos nos moldes do que foi pedido aos alunos, desenhos realizados com o objetivo de nos explicar os espaços destinados ao brincar naquela escola.

\section{Algumas dificuldades vivenciadas em campo}

Duas dificuldades foram observadas nos mapas vivenciais com crianças de 6 anos:

1. A quantidade de desenhos a serem realizados pareceu cansá-las, de forma que algumas preferiam conversar a desenhar.

Para lidar com essas dificuldades, deixamos algumas crianças livres para representar sucintamente o que diziam no desenho, sem se preocuparem com a forma ou com a aparência, dando, assim, maior importância ao que falavam do que ao que desenhavam.

2. Todas as crianças desenharam sobre a primeira folha a parte externa da escola, o que dificultava a aplicação da folha transparente para desenhar os espaços do brincar dentro da escola.

O fato de registrar a parte externa da escola pode ter acontecido pela interpretação da demanda que, talvez, não tenha sido suficientemente clara. Portanto, parece-nos também que a parte externa da escola é representativa para as crianças e o fato de poder desenhar o nome da escola é importante, assim como as cores que identificam a escola e a imagem do prédio. Acreditamos que a parte externa dê mais identidade à escola, diferenciando, com maior êxito, essa instituição de outras onde tenham frequentado.

Podemos notar que existe uma necessidade de identificação da escola por meio dos desenhos da parte externa, o que, finalmente, respeitava a demanda de representação da escola real. Percebendo que o desenho da parte externa era importante e, não querendo induzir ou interferir na condução dos desenhos pelas crianças, deixamos que elas utilizassem o papel transparente como papel comum, não o utilizando da forma mencionada na metodologia (por superposição), mas sem o desenho da escola como suporte. Estávamos em acordo com o expresso por Lopes (2015, no prelo):

Os mapas vivenciais não se organizam por uma estrutura metodológica rígida, mas com trilhas esboçadas tendo o objetivo da pesquisa como referências e na afirmação que as crianças criam suas culturas na unidade pessoa-meio, na 
vida social dialogada com a formaçáo cultural, com isso, busca-se mapear as lógicas pessoais e coletivas, indícios que se expressam em determinadas temporalidades e especialidades.

\section{0 que as crianças nos mostram em seus desenhos e falas}

O desenvolvimento não segue para a socialização, mas para a individualizaçáo de funçóes sociais (transformação das relaçôes sociais em funçôes psicológicas) [...]geralmente perguntam como esta ou aquela criança se comporta no coletivo. Nós perguntamos: como o coletivo cria nesta ou naquela criança as funçôes superiores? (VYGOTSKY, 2000, p. 28-9).

Muito já se falou em socialização das crianças. Diferentes olhares evidenciam diversas posiçóes e formas de se conceber esse processo. Vygotsky, na epígrafe, explicita a sua, nem sempre compartilhada com outros autores. Dubet e Martuccelli (1996), por exemplo, apoiando-se no trabalho de Jean Piaget, afirmam que as crianças muito pequenas se encontram em um momento em que a voz do mestre é quase indiscutível pelo estado de heteronomia dessas crianças com relação às regras e à autoridade. É somente na idade de 7-8 anos até a adolescência que Piaget localiza o estágio das operaçóes concretas, ou seja, o aparecimento das funçôes racionais que permitem, por exemplo, a distância e o esforço de subjetivação que Dubet e Martuccelli apresentam como condição para que a criança possa expressar legitimamente sua experiência.

Cremin e Slatter se opóem a essa visão da criança pequena. Segundo os pesquisadores, as crianças pequenas são legitimamente capazes de ser sujeitos das suas palavras e de expressar conscientemente seus sentimentos e pensamentos sobre o que se passa na escola. Por que o sentido da experiência social e escolar da criança pequena não seria legítima? O que podemos observar é uma supervalorização das funçóes racionais para que a palavra da criança possa ser considerada.

No presente trabalho, consideramos a criança como ela é: geohistoricamente referenciada, sem a reduzir a um indivíduo pré-lógico, tipificado previamente. Criadora da vida e do mundo, na interface do mundo, do social e da cultura, ou seja, a criança pequena é vista como um sujeito de linguagem, capaz de falar da sua experiência e vivências no mundo, em um ser e estar no tempo, que é sempre histórico, e em um espaço, que é sempre geográfico, dos quais emergem 
suas lógicas expressivas, potentes e diferenciadas das do discurso formal do adulto ou das crianças mais velhas.

Desse modo, na pesquisa realizada, o objetivo das conversas e da confecção dos desenhos foi estabelecer diálogos, promover escuta, buscando compreender e respeitar o que dizem, seus sentimentos, sua visäo das coisas, seus pensamentos, enfim, considerá-las como pessoas que fazem inteiramente parte do espaço institucional no qual são educadas e, também, educam. Assim como a socialização, o desenho tem sido território de disputa e diferenças. Segundo Sarmento (2007, p. 57):

[...] a cultura escolar é o espaço de formalização do desenho infantil, mesmo quando ele é promovido enquanto 'desenho livre' ele é ainda considerado como uma tarefa escolar, condicionado pelo seu caráter compulsivo, pela sua estrutura espaço-tempo dentro da qual é realizado, pelo tipo de material utilizado, etc.

Não devemos esquecer que, na escola, as crianças encontram também seus pares. "O desenho infantil recebe da cultura da escola sobretudo a sua sintaxe, as regras de sua estruturação plástica e a permeabilidade aos sujeitos e motivos comuns gerados na cultura de pares, pelas relaçóes com seus colegas", nos diz Sarmento (2007, p.15).

Maria Isabel F. P. Leite, na sua tese intitulada Nem fase de grafismo, nem exercício psicomotor: o desenho como espaço de produçáo cultural de crianças, coloca ênfase no desenho como espaço de produção cultural das crianças. A autora critica o fato de que, ainda hoje, na maioria das instituiçóes, as práticas são baseadas na perspectiva das teorias do desenvolvimento gráfico utilizadas como meio de medida e de avaliação das crianças. Segundo a pesquisadora, as referências da Educação, da Psicologia e das Ciências Sociais, em geral, colocam ênfase na maioria dos casos em aspectos dos desenhos que limitam as crianças e as aprisionam em fases ou etapas, pedagogizando suas criaçóes, destituindo-as de seus aspectos expressivos e livres. Na melhor das hipóteses, os desenhos são vistos como documentos. Os educadores sentem a necessidade de ser guiados, seguindo os parâmetros de medida certificados, efetuando, muitas vezes, uma leitura rápida das teorias dos pesquisadores e colocando a criança em uma posição de aluno pré-operatório, silábico, etc.

Esse tipo de olhar esquece as condiçôes pessoais de produção quando afirma que é o desenvolvimento cognitivo e/ou psicomotor que determina o nivel do desenho, devendo a criança evoluir a uma outra etapa, considerada como mais madura. 
Ao contrário, Sarmento (2007) considera os desenhos como artefatos culturais, que incorporam diferentes fontes de produçóes culturais. Assim, somos convidados a interpretar cada desenho na sua diversidade de formas e cores, simultaneamente, como um produto singular de criação de um sujeito concreto - a pessoa que desenhou; um artefato social significativo das regras e valores culturais de inserção da criança; um objeto simbólico que exprime o grupo geracional específico - a infância -, dividido em subgrupos de idade com capacidades e habilidades gráficas diversas. Essa teoria simbólica da qual trata Sarmento aloca o desenho das crianças como atos de inscrição de uma cultura. Quando a criança quer trazer o mundo por meio de um desenho, o que ela desenha é permeado pelos códigos culturais nos quais ela vive.

Sarmento aborda ainda a existência de esferas simbólicas com as quais as crianças fazem uma montagem para interpretar o que vivem. Nos desenhos, por exemplo, podemos perceber os símbolos da cultura rural quando a criança mora em um meio rural (chapéus, animais), o que representa sua cultura local. Podemos também encontrar lendas que influenciam seus desenhos (cultura nacional). Ou mesmo uma colonização do imaginário infantil, dentro de uma cultura global, pelos diversos programas de televisão, séries, desenhos animados, filmes, produtos destinados às crianças. Portanto, cabe observar que essa colonizaçâo não quer dizer uma recepção passiva pelas crianças, vez que elas não são puramente impregnadas pelos produtos, elas agem criticamente e interpretam essa cultura de massa.

É também importante dizer que os desenhos das crianças não representam simplesmente a realidade exterior (o realismo virtual - última etapa da escala evolutiva, segundo a concepção evolucionista dos trabalhos em psicologia). A criança não procura sempre reproduzir o real. Ela não é inferior ou menos desenvolvida que o adulto por causa dessa falta de realidade nos seus desenhos.

Segundo Mattews (2003), de forma geral, mesmo quando as crianças tentam encontrar uma similaridade entre seus desenhos e a realidade (como, por exemplo, quando elas desenham nuvens, flores e animais), elas reinventam formas imaginárias e misturam também elementos fantasistas com um sentido e objetivos bem distanciados dessa presumida intencionalidade realista.

Nos desenhos, podemos encontrar diversos códigos culturais, às vezes contraditórios, mas que fazem parte da vida das crianças: sua cultura familiar e escolar, a cultura local, global e nacional. Diversos espaços e tempos são cruzados, amalgamados, escalas diversas encontram-se nas fronteiras, sobrepóem-se. As crianças não reproduzem linearmente as formas que percebem nos seus contextos de socialização, elas os interpretam, elas ressignificam e dão aos desenhos formas plásticas próprias que mostram suas visóes particulares e singulares sobre o mundo. 
Nós, referenciados no conceito de reelaboração criadora de Vygotsky (2009), descrito por esse autor nos anos 30 do século passado, reconhecemos os desenhos infantis como uma das múltiplas linguagens formadoras do humano e, portanto, da criança. Ou seja, acreditamos que constituem um momento explícito de criação do inexistente, da criança como narradora da vida e criadora da própria vida.

Por isso, essa pesquisa pautou-se em uma perspectiva metodológica, conforme explicitada anteriormente, que vem sendo reconhecida por mapas vivências, onde combinamos as falas infantis e seus registros.

\section{A escola segundo as crianças: o recreio de lá é mais legal, porque lá tem brinquedo}

Quando pedimos às crianças que desenhassem a escola, todas elas trouxeram a sua parte externa, como aparece na imagem a seguir:

\section{llustração 1}

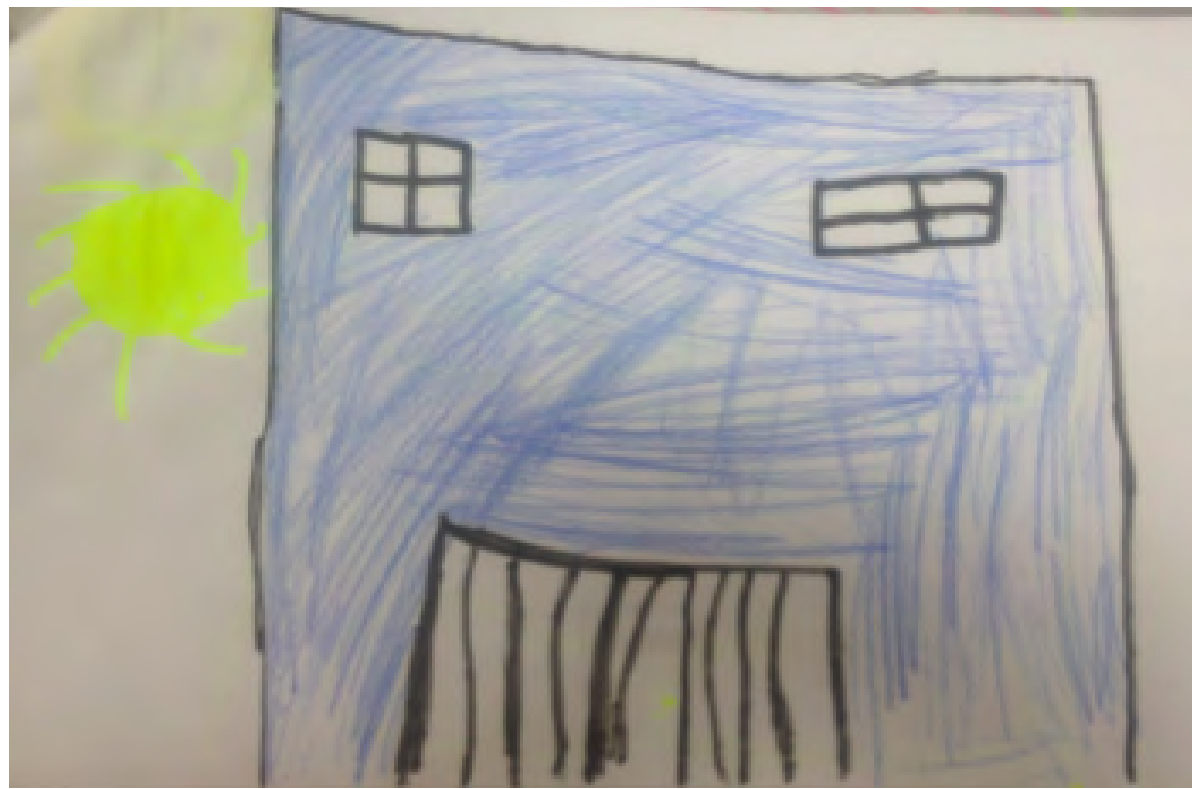

Fonte: trabalho de campo - 2014 
Na maioria dos desenhos, existem grades, sejam elas na porta de entrada, ou nas janelas. Evocando a questão das grades, Ana diz:

Ana: A gente está dentro da sala, eles fecham, sabe?

Pesquisadora: Ah, para ninguém entrar?

Ana: Entrar não, fugir!!

Se ouvimos as crianças, podemos perceber, nos seus discursos, uma perspectiva de escola como um lugar em que elas só ficam estudando, onde existem muitas regras e obrigaçôes e onde elas não fazem nada de bom.

Alice fala da escola dizendo que, dentro dela, elas só ficam correndo, certamente remetendo ao tipo de brincadeira mais comum pela falta de brinquedos e de espaço destinado às crianças.

A escola, para essas crianças, ainda está muito relacionada à questão do brincar. Elas gostam da escola porque brincam, ou não gostam porque as brincadeiras são palhas ${ }^{4}$, ou porque não existem brinquedos. Muitas delas dizem preferir as brincadeiras fora da instituição, fazendo referência justamente ao caráter livre e às opçóes que têm com relação aos diversos brinquedos.

A aluna começa falar de uma escola onde estudara...

Pesquisadora: O que tinha de bom lá?

Sofia: Lá tem lanche, que você não precisa comprar lanche!

Pesquisadora: Hum... O que mais?

Sofia: O recreio de lá é mais legal, porque lá tem brinquedo, lá!

O que é ressaltado nas falas das crianças nessa escola é a necessidade de encontrar estratégias para lidar com o espaço sem opçóes de brincadeiras.

\section{Os espaços de brincar: estratégias em uma escola sem brinquedos}

Apesar de constatar que, nessa escola, não existem brinquedos, as crianças encontram maneiras de se divertir, seja entre colegas no recreio ou em determinadas aulas.

4 Palha ou paia: gíria utilizada para designar algo sem atrativo, sem graça. 
Pesquisadora: E onde mais vocês brincam aqui, tem o recreio e o quê mais, tem outro lugar para brincar? Helena: Eu e minhas amigas conversamos...

No recreio as crianças brincam de amarelinha, pique-pega, cobracega, pique-boia, pique-queimada, de espiâo, pique-gelo, polícia e ladrão, tocha humana, queimada. Cabe aqui notar que todas são brincadeiras cujo material principal é humano. Elas só precisam que os colegas estejam de acordo com a escolha da brincadeira ${ }^{5}$ para começarem a brincar. O recreio é considerado um local livre, ou seja, as brincadeiras são escolhidas pelas crianças. Portanto, muitas delas reclamam de ter que dividir o local com crianças maiores, o que dificulta, pois, segundo Aline, "algumas vezes ocorrem brigas e empurra-empurra."

Vejamos o que dizem também Helena e Clara:

Pesquisadora: Aí vocês brincam de Polícia e Ladrão, e qual a outra brincadeira que vocês inventam?

Helena: Eu e minhas amigas, ficamos lá paradas! Às vezes a gente fica correndo atrás do menino do $2^{\circ}$ ano, ele fica atrás da gente! Ele só aparece na hora errada, quando a gente tá brincando.

Pesquisadora: E você?

Clara: Eu acho que o nome dele é Camilo! Eu fico brincando lá. Aí depois tem gente que fica brincando comigo sem me avisar, aí eu fico brigando!

Quando Clara diz que seus colegas não a avisam quando estão brincando, isso quer dizer que existe um código entre eles que, mesmo não sendo clara e explicitamente dito, deve ser cumprido para que não haja problemas. Camilo não avisa que está brincando e isso irrita Clara, que, sem saber que é brincadeira, considera o contato como agressáo.

O campinho, um pequeno espaço com grama sintética situado na entrada da escola, onde se vê uma pequena amarelinha pintada, é também citado como o melhor local para se brincar, onde todo mundo pode correr sem se machucar e onde se pode tirar o sapato... e se você cai, náo rala o joelho.

5 Este é um fato importante. Se as crianças não estiverem de acordo, por exemplo, sobre quem será a polícia ou o ladrao, a brincaderia se torna impossível de ser concretizada, segundo o que diz Clara. 


\section{Foto 1: 0 campinho}

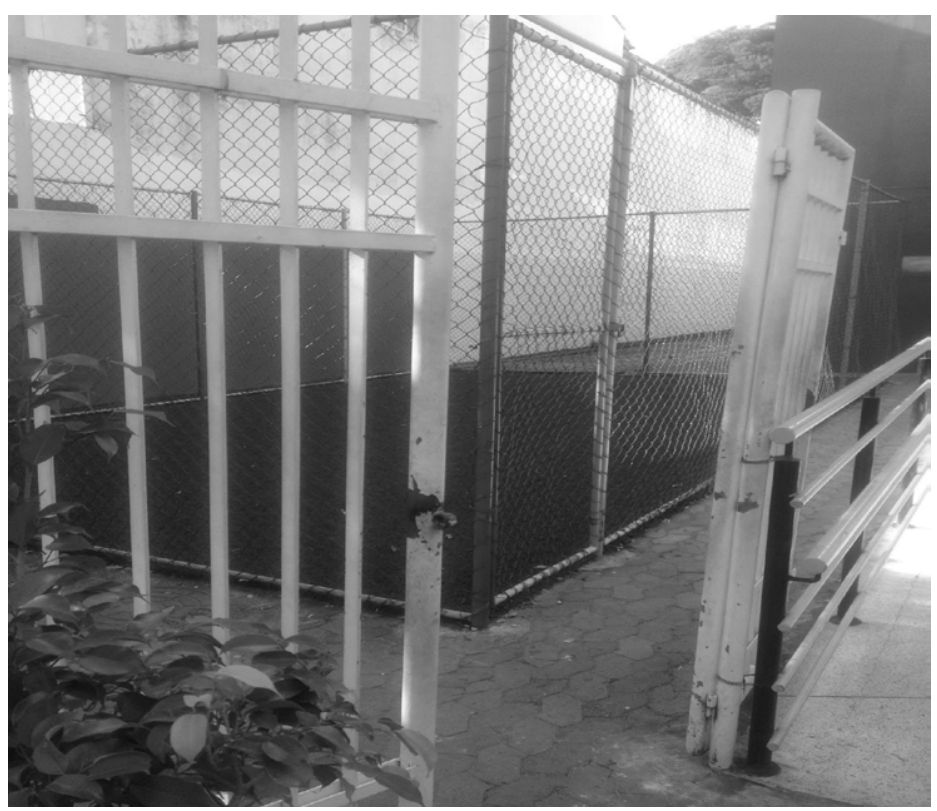

Fonte: produção dos autores

Ilustração 2: A amarelinha está representada à direita da escola

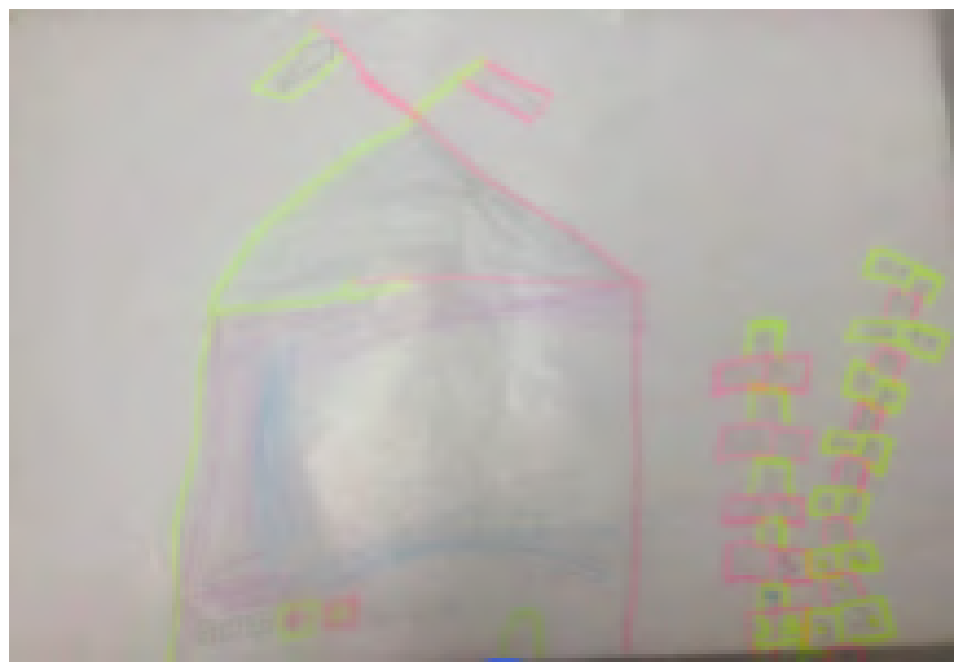

Fonte: trabalho de campo, 2014. 
Esse espaço é utilizado pela professora de Educação Física, que leva cada turma em um horário diferente. Esses fatores juntos (grama, presença de uma só turma, brincadeiras) fazem com que esse local e essa aula sejam mencionados pela maioria dos alunos entrevistados como as melhores.

Pesquisadora: E o que tem de bom nessa escola que vocês acham?

Carlos: Educação Física!

Pesquisadora: O que que tem na Educação Física entáo que você falou que gosta?

Carlos e Eduarda: Brincadeiras - respondem as duas crianças juntas!

Pesquisadora: É? E o que que vocês brincam?

Eduarda: Queimada, nos dias da queimada as meninas ganharam!

A aula de informática é também muito citada, por várias razões. É o lugar onde as crianças vão quando está chovendo... que molha, quando a gente está fazendo nada também, informática, e onde se brinca na maior parte do tempo: a gente só brinca (o que às vezes é criticado pelas crianças, que falam que $o$ tio não póe jogos ou a gente fica lá jogando um jogo palho).

A biblioteca, mencionada como lugar melhor que o recreio, só aparece na fala de duas crianças. Portanto, é interessante perceber que a biblioteca é citada não para a leitura, mas por ser um lugar silencioso, se comparado ao recreio, mesmo se o silêncio é quebrado quando a professora se ausenta.

Pesquisadora: E por que que a biblioteca às vezes é melhor do que no recreio?

Sofia: É que na biblioteca é mais quietinha.

Helena: Na minha escola, quando a tia sai, todo mundo fica gritando. Eu não, fico lá quietinha.

Pesquisadora: É... a professora sai, fica todo mundo falando! Helena: Aí eles ficam olhando na porta, quando tia chega, eles ficam olhando na porta, aí fica todo mundo quietinhos.

Nas falas das crianças percebemos que a falta de brinquedos gera a necessidade de brincadeiras em que elas devem estar sempre entre colegas, o que causa, também, dificuldade em certas crianças no recreio, seja pelo barulho, seja pela obrigação do contato com alunos maiores, seja pela dificuldade de entendimento nas brincadeiras escolhidas. 
Segundo Corsaro (1997), nos primeiros anos da pré-escola as crianças sempre tentam proteger os seus espaços de interação. De acordo com o autor, nas pré-escolas, as crianças se divertem simplesmente porque elas fazem coisas juntas. Porém, isso demonstra ser um desafio para elas. Elas passam muito tempo criando, protegendo e ganhando acesso às atividades e rotinas dos pares. Proteger os seus espaços de interação é uma tendência diretamente ligada à fragilidade das suas interaçôes entre pares, às diversas possibilidades de perturbação, podendo as crianças manter o controle das atividades compartilhadas.

Fica claro também, nas entrevistas, que gostar ou não gostar de um lugar na escola depende do relacionamento entre os colegas, porque são eles que criam a possibilidade de brincar.

Pesquisadora: Ah, entáo você ficou seu recreio na biblioteca?! Você gosta lá da biblioteca?

Clara: É, mas eu não gosto de ficar lá.

Pesquisadora: Por quê?

Clara: Porque quase não tenho nenhuma amiga...

Pesquisadora: Não tem amiga?

Clara: Eu só tenho Bia, Ane..., mas a Ane ignora eu.

Pesquisadora: Mas por quê?

Clara: Por que eu irrito ela um pouquinho.

Pesquisadora: $\mathrm{O}$ que você faz pra irritar ela?

Clara: Não, é que eu fico imitando ela, falando toda hora com ela, aí eu às vezes fico falando: "Por quê, por quê, Por quê" toda hora nela.

Pesquisadora: Aí ela fica irritada por que você fica perguntando muito?

Clara: É, meu irmão faz isso comigo.

Em outra conversa:

Pesquisadora: Então, como que era, quais as diferenças da creche e aqui?

Carlos: [....] Estou com saudades!

Pesquisadora: Você está com saudades?

Carlos: Estava com saudades da Ana Beatriz

Eduarda: A minha creche é chata!

Pesquisadora: É chata?

Eduarda: A minha creche é! Aqui é melhor!

Pesquisadora: Qual a diferença? Por que ela é chata?

Eduarda: Um dia o menino lá da minha creche me agarrou por trás, ele se deu mal, eu dei um chute no saco dele, ele quase saiu rolando! [...] 
Eduarda: Na minha creche a Educação Física era chata!

Pesquisadora: Por que?

Eduarda: Porque não tinha nada para fazer! Só tinha que correr pra lá e pra cá!!

Carlos: Na minha creche era legal demais, tinha parquinho! Eduarda: Eu sempre quis pegar os meninos, eles enchiam o saco me chamando de "a gatinha do papai". Um dia fiquei tão nervosa que eu até chorei!

Pesquisadora: É, mas e aí?

Eduarda: Minha cabeça tava quente, dava vontade de bater neles!

A entrevista com Eduarda e Carlos nos mostra que o fato de gostar ou não da escola e das aulas está vinculado às possibilidades de brincadeira que elas oferecem e ao relacionamento das crianças com seus colegas. Como nos mostram as falas das crianças, o relacionamento entre os colegas é central nessa idade. Os desenhos também mostram essa questão: nas representaçôes sobre os espaços de brincar, a presença maior é dos colegas. Encontramos também desenhos do campinho e da amarelinha.

\section{A escola que desejo: o mundo das fadas}

$\mathrm{Na}$ escola ideal das crianças entrevistadas existem vários brinquedos. Sempre que elas pensam em uma escola ideal isso se dá em termos de um maior número e diversidade de possibilidades de brincar, sejam mais aulas de Educaçâo Física, um campo de futebol, pescaria, piscina, etc. Sofia revela também outro desejo: "Eu vou fazer um barquinho, do lado dessa escola aqui que parece uma casa"[...] "Olha aqui, minha casa, minha escola." Ela fala, inclusive, da presença de uma cama na escola. Carlos revela sua vontade de voltar para a casa e para a creche, desejo esse vinculado à liberdade de brincar.

Pesquisadora: Então é pique-pega, pique-alto, polícia e ladrão! E o que é que podia ter nesse recreio aí que não tem que vocês iriam gostar?

Carlos: A gente podia sair dessa escola!

Pesquisadora: E ir pra onde?

Carlos: Pra casa!

Pesquisadora: A é?! Mas aí vocês não estariam na escola, né?!

Carlos: Meu sonho é ir para creche de novo!

Pesquisadora: Ah é?! 
Eduarda: Credo!

Pesquisadora: O que você fazia lá de legal?

Carlos: Eu podia desenhar no quadro, podia brincar na areia!

Outro desejo relatado é vinculado à fantasia de viver no mundo das fadas, no qual as crianças não precisariam estudar para aprender, elas já nasceriam sabendo. A única coisa que caberia a elas seria brincar. $O$ professor estaria presente para ensinar magias às crianças.

Eduarda: Aqui é a saída das fadas!

Pesquisadora: E o que elas faziam aí dentro?

Eduarda: Brincavam!

llustração 3 - No mundo das fadas, a escola ideal

Fonte: trabalho de campo - 2014 


\section{llustração 4 - Podemos voar!}

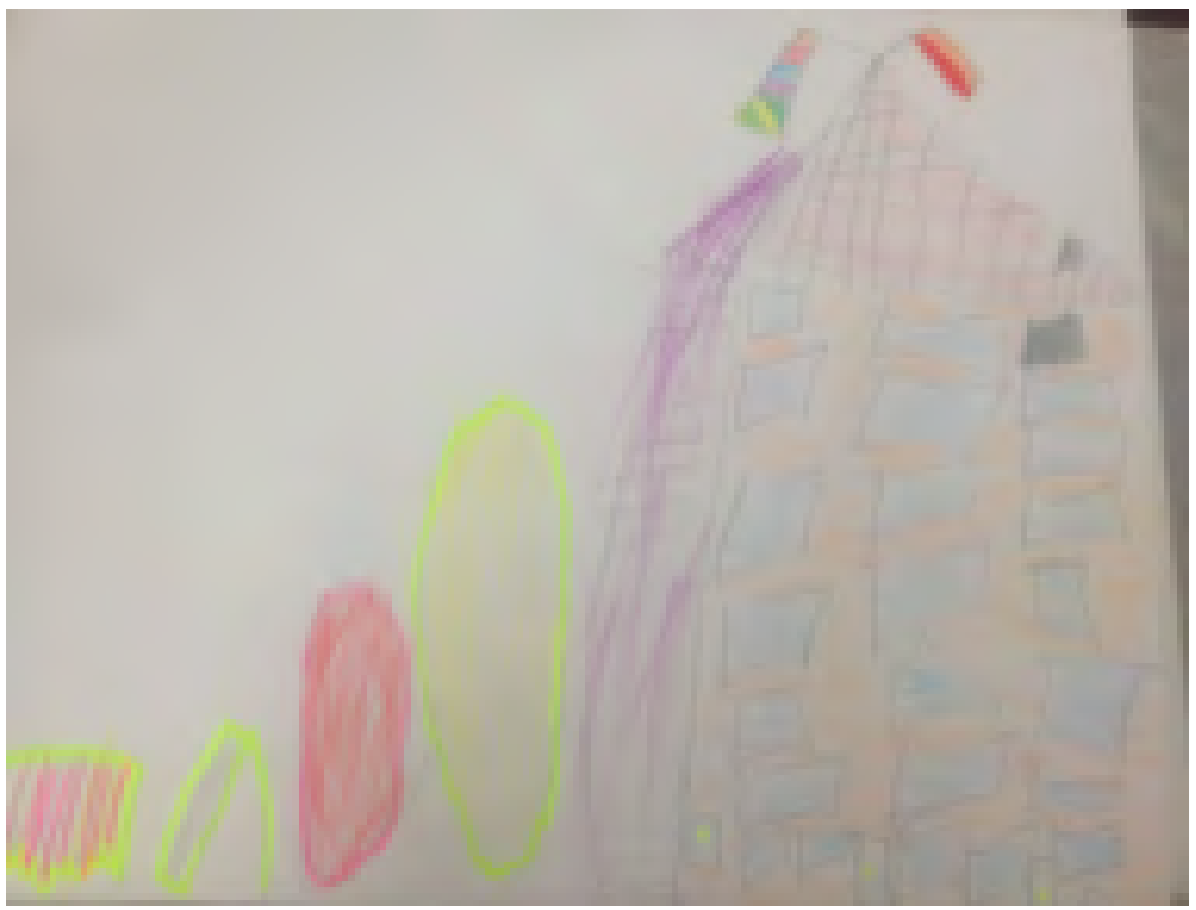

Fonte: trabalho de campo - 2014

Interessante perceber que, na maioria dos desenhos da escola ideal, encontramos registros de brincadeiras ou de brinquedos. É nítida a diferença entre esses desenhos e os outros dois (escola real e espaços de brincar). Aqui as crianças podem "voar", como diz Eduarda.

\section{Algumas considerações para fechar as falas ... por enquanto!}

Alguns pontos importantes podem ser ressaltados nesta investigação:

1. a escola é apresentada como espaço fechado no qual as possibilidades de brincadeira são mínimas;

2. o fato de gostar ou não gostar de uma aula ou mesmo da escola é diretamente relacionado às oportunidades de brincadeiras que são oferecidas;

3. as crianças criam estratégias para lidar com um espaço sem brinquedos; 
4. o fato de, nesta escola, os espaços lúdicos serem restritos cria uma necessidade de socialização, de convívio e de negociação grande entre as crianças;

5. os desenhos da escola ideal mostram claramente a importância e o interesse das crianças de 6 anos pelo brincar.

A importância do brincar para as crianças do $1^{\circ}$ ano de Ensino Fundamental deve ser considerada. A passagem do ensino pré-escolar para a escola ou mesmo da casa para a escola (no caso de algumas das crianças) é também uma passagem de um espaço mais lúdico a um espaço formal, seguindo uma forma escolar ${ }^{6}$, muitas vezes nunca vivenciada pela criança. Essa situação do espaço mais formal é relatada pelas crianças, que parecem viver o espaço escolar mais como um espaço do náo brincar do que como espaço fundamental para a aprendizagem e o desenvolvimento.

A questáo do brincar para as crianças de 6 anos na escola está presente nos documentos de orientaçóes para a ampliação do ensino de 8 para 9 anos. O Referencial Curricular Nacional para a Educação Infantil (RCNEI) considera o brincar como atividade fundamental para o desenvolvimento global da criança. Segundo este documento "a brincadeira favorece a auto-estima das crianças, auxiliando-as a superar progressivamente suas aquisiçōes de forma criativa." (BRASIL, 1998, p. 27). Nesse sentido, a transição da educação infantil para o ensino fundamental deveria ter como base a continuidade dos processos educativos, portanto, vê-se uma focalização nas tarefas escolares em detrimento do brincar.

Segundo Correa (2008), os espaços das escolas, assim como a planificação das aulas, não contribuem para a viabilização do brincar no ensino fundamental. Para a autora :

Se tomarmos como parâmetro a criança de seis anos - mas não apenas ela, já que as crianças não "amadurecem" com sete - devemos ter em vista algumas de suas características peculiares: a importância do brinquedo e da brincadeira para elas, bem como as condiçôes de aprendizagem em face de seu desenvolvimento, seu vínculo familiar e, como decorrência disso tudo, a necessidade de estratégias

6 Segundo Vincent, Lahire e Thin (1994), o que se intitula forma escolar se caracteriza por: um espaço separado, com material estruturado de acordo com exigências educativas, uma ordem escolar impessoal, exercícios repetitivos, uma organização pedagógica, etc. 
de ensino que se coadunem com tais características. (CORREA, 2008, p. 13).

As falas das crianças, que deixam explícitas as amálgamas entre espaço escolar, brincadeiras e formas escolares, local em que passam uma grande parte de suas vidas, levam-nos a pensar um conceito para olhar e compreender suas vivências: sitios geográficos brincantes ${ }^{7}$, eis um dos grandes achados dessa pesquisa e que irá nos guiar para outras. Para nós, neste momento, fica claro que nos territórios oficialmente estabelecidos do ofício escolar, a criação desses sítios permite a emergência de uma das atividades criadoras humanas mais significativas e que, segundo Vygotsky (2009), é um dos alicerces da imaginação: o brincar. Esperamos que esse conceito e os aprofundamentos dele que estão por vir, possam ser incorporados nas lógicas adultas, para compreender e respeitar a vida das crianças, potencializando a infância.

\section{Referências}

BARROS, M. O livro das ignoráças. Rio de Janeiro: Record, 2001.

BARROS, M. Memórias inventadas - As Infâncias de Manoel de Barros. São Paulo: Planeta do Brasil, 2010.

BRASIL. Ministério da Educação. Secretaria de Educação Fundamental. Referenciais curriculares nacionais para a educaçáo infantil. v. 1. Brasília: MEC/SEF, 1998.

CORREA, B. C. Crianças aos seis anos no ensino fundamental: desafios à garantia de direitos. In: 30 Reuniáo Anual da ANPED, 2008, Caxambu. 30 anos de pesquisa e compromisso social. Anais [...]. Caxambu: ANPED, 2008.

CORSARO, W. The Sociology of Childhood. London: Pine Lorge Press, 1997.

CREMIN, H.; SLATTER, B. It is possible to access the 'voice' of pre-school Children? Results of a research project in a pre-school setting. Educational Studies. Inglaterra, v. 30, n. 4, p. 457-470, dez. 2004.

DELALANDE, J. O indivíduo social, outra realidade, outra sociologia? Pensar o

7 A palavra sitio, na Geografia, designa de forma geral um espaço ocupado, situado a partir de alguma referência que o dá existência. Podemos falar, por exemplo, em sítio urbano de uma cidade, por isso usamos esse termo no conceito que apresentamos. 
indivíduo, pensar as relaçôes sociais, repensar a sociologia. In : XVII Congresso Internacional da AISLF. Resumos do grupo de trabalho GT 20. Anais [...]. Tours, 2004, p. 5.

DENZIN, N.K. Childhood Socialization. S. Francisco: Jossey-Bass, 1977.

DUBET, F. Sociologie de l'expérience, coll. La couleur des idées, Paris : Ediçóes du Seuil, 1994.

DUBET, F.; MARTUCCELLI, D. A l'école. Sociologie de l'expérience scolaire. Paris: Edições du Seuil, 1996.

JAMES, A.; JENKS, C.; PROUT, A. Theorizing Chidhood. Cambridge: Polity Press, 1998.

LEITE, M. I. Nem fase de grafismo, nem exercicio psicomotor: o desenho como espaço de produção cultural de crianças. In: Machado, M. L. (Org.). Encontros e Desencontros em Educaçao Infantil. São Paulo: Cortez, 2005, p.268-274.

LIMA, Reinaldo J. de. Mapa de areal: cartografia com crianças. Disponível em: http://www.grupeci.fe.ufg.br/up/693/o/RE29.pdf. Acessado em 12.08.2019

LOPES, J. J. M. Os bebês, as crianças pequenas e suas condiçôes históricogeográficas: algumas notas para o debate teórico-metodológico. Educaçáo em Foco, Juiz de Fora, edição especial, p. 151-161, agosto de 2012.

LOPES, J. J. M. Mapa dos cheiros: cartografia com crianças pequenas. Revista Geografares, Vitória, n. 12, p. 223-224, jul. 2012.

LOPES, J.J.M. Geografia da Infância, Espaços Desacostumados e mapas vivências in SANTOS, Maria Walburga dos, TOMAZETTI, Cleonice Maria, MELLO, Suely (Org). "Eu ainda sou criança! Educaçáo Infantil e Resistência”. Sáo Carlos: Ed. UFSCAR. 2015, no prelo.

MATTHEWS, J. Drawing and Painting. Children and Visual Representation. (2th. Ed.) London: Chapman Pub, 2003.

MUCHOW, M.; MUCHOW, H. H. Der Lebensraum des Großtadtkindes. Doutschland: Beltz Juventa., 2012.

PRADO, A. Terra de Santa Cruz. Rio de Janeiro: Nova Fronteira, 1981.

PRADO, M.R. La scolarisation en maternelle: une analyse du récit et des dessins d'enfant. Cahiers du CERFEE, Paris, n.50, p. 20-35, 2018.

PIAGET, J. A formaçáo do símbolo na criança. Rio de Janeiro: Zahar, 1971. 
PROUT, A. The Body, Childhood and Society. London: MacMillan Press, 2000 .

PRESTES, Z. Quando náo é quase a mesma coisa: traduçóes de Lev Semionovitch Vigotski no Brasil. Campinas, SP: Autores Associados, 2012.

SARMENTO, M. J. As culturas da infância nas encruzilhadas da segunda modernidade. In: SARMENTO, M. J.; CERIZARA, A. B. Crianças e miúdos: perspectivas sociopedagógicas da infância e da educação. Porto: ASA, 2004, p.934.

SARMENTO, M. J. Conhecer a Infância: Os Desenhos das Crianças combo Produções simbólicas. Lição de Síntese de Provas de Agregação. Braga: Universidade do Minho, 2007.

SIROTA, R. L'émergence d'une sociologie de l'enfance : évolution de l'objet, évolution du regard, Education et Société, Paris, n. 2, p. 9-33, 1998.

VYGOTSKY, L. S. (2000). Manuscrito de 1929. Educação \& Sociedade, 21(71), 21-44. Recuperado em 16 de maio de 2012, de http://www.scielo.br/scielo. php?script=sci_artte

xt\&pid=S0101-73302000000200002\&lng=pt\&nrm=iso\&tlng=pt

VYGOTSKY, L. S. A brincadeira e o seu papel no desenvolvimento psíquico da criança. Trad. Zóia Prestes. Revista Virtual de Gestáo de Iniciativas Sociais, Rio de Janeiro, n. 8, p. 23-36, 2008.

VYGOTSKY, L. S. Imaginação e criação na infância. São Paulo: Ática, 2009.

VYGOTSKY, L. S. Quarta aula: a questão do meio na pedologia. Tradução de Márcia Pileggi Vinha. Psicologia USP, São Paulo, v. 27, n. 4, p. 681-701, 2010. VINCENT, G.; LAHIRE, B.; THIN, D. L'Education prisonnière de la forme scolaire? Scolarisation et socialisation dans les sociétés industrielles. Lyon: Presses Universitaires de Lyon, 1994. 